\title{
The role of coastal ocean variation in spatial and temporal patterns in survival and size of coho salmon (Oncorhynchus kisutch)
}

\author{
Alistair J. Hobday and George W. Boehlert
}

\begin{abstract}
Interannual and decadal variability in ocean survival of salmon are well known, but the mechanisms through which environmental variability exerts its effects are poorly understood. Data on hatchery-reared coho salmon (Oncorhynchus kisutch) from individual releases (1973-1998) along the species' entire North American range were analyzed to provide information on survival and size. Three geographic regions (north of Vancouver Island, Puget Sound and Strait of Georgia, and the outer coast south of the tip of Vancouver Island) showed coherent trends in survival and size of returning fish. Within each region, multivariate nonlinear models were used to relate coho survival and final size to spatially and temporally tailored environmental variables at time periods of release, jack return, and adult return. The most important environmental variable, as indicated by the highest amount of variance explained, was a calculated proxy for mixed-layer depth, followed by sea level. In all regions, survival and adult size were most influenced by environmental conditions at the release time. A shallow mixed layer was associated with increased survival and decreased size in all regions. Improved understanding of the relationship between environmental conditions and size and survival of coho salmon provides insight into production patterns in the coastal ocean.
\end{abstract}

\begin{abstract}
Résumé : La variation d'une année à l'autre et d'une décennie à l'autre de la survie des saumons en mer est un phénomène bien connu, bien que les mécanismes par lesquels la variabilité de l'environnement peut agir restent mal compris. L'analyse de données provenant d'empoissonnements individuels (1973-1998) de Saumons cohos (Onchorhynchus kisutch) de pisciculture sur toute l'étendue de la répartition géographique de l'espèce en Amérique du Nord a fourni des renseignements sur la survie et la taille. Trois régions géographiques (le nord de l'île de Vancouver, Puget Sound et le détroit de Géorgie, ainsi que la côte extérieure au sud de l'extrémité de l'île de Vancouver) affichent des tendances cohérentes dans la survie et la taille des poissons qui rentrent de la mer. Dans chaque région, des modèles multidimensionnels non-linéaires ont permis de relier la survie et la taille terminale des saumons aux variables de l'environnement correspondant, dans le temps et l'espace, aux périodes d'empoissonnement, de retour des saumoneaux et de retour des adultes. Les variables de l'environnement les plus importantes, qui expliquent le maximum de variance, sont d'abord une valeur indirecte calculée de la profondeur de la couche mixte, puis le niveau de la mer. Dans toutes les régions, la survie et la taille des adultes sont affectées surtout par les conditions de l'environnement au moment de l'empoissonnement. Une couche mixte de faible profondeur est associée à une augmentation de la survie et à une diminution de la taille dans toutes les régions. Une meilleure compréhension des relations entre les conditions de l'environnement et la taille et la survie des Saumons cohos permet une connaissance des patterns de production dans l'océan côtier.
\end{abstract}

[Traduit par la Rédaction]

\section{Introduction}

Environmental variability affects production in fish stocks, often in predictable ways and often with greatest impact on early life-history stages (Houde 1997). The relationships can become more complex for species inhabiting or migrating

Received October 17, 2000. Accepted August 28, 2001.

Published on the NRC Research Press Web site at

http://cjfas.nrc.ca on October 5, 2001.

J16022

A.J. Hobday ${ }^{1,2}$ and G.W. Boehlert. NOAA/NMFS

Southwest Fisheries Science Center, Pacific Fisheries

Environmental Laboratory, 1352 Lighthouse Avenue,

Pacific Grove, CA 93950, U.S.A.

${ }^{1}$ Corresponding author (e-mail: Alistair.Hobday@marine.csiro.au).

${ }^{2}$ Present address: CSIRO Marine Research, P.O. Box 1538,

Hobart, Tasmania, 7001, Australia. through a broad geographic range; the diversity of environmental factors impacting survival may vary with location or with life-history stage. For species with a high level of "population richness", localized and often self-sustaining populations may have larval and older life stages retained in areas that are characterized by different environmental features (Sinclair and Iles 1988); thus, survival and growth among populations may respond to different types of physical forcing. Recognizing the scale of physical forcing remains a goal for fisheries oceanography.

Production of marine fish like salmon is influenced by three processes: survival, age at maturity, and size (growth) (Peterman et al. 1998; Pyper et al. 1999). Variability in these components is well documented on a range of spatial and temporal scales (Steele 1996). At the ocean basin scale, correlations exist between atmospheric and oceanographic indices (i.e., the Aleutian Low Pressure Index, North Pacific Index, Pacific Decadal Oscillation, and Southern Oscillation 
Index) and time series of catch of North Pacific salmon stocks (e.g., Mantua et al. 1997), but the actual combination of physical and biological processes that determines these linkages has not been identified (Beamish et al. 2000). These higher-order processes are assumed to influence the environment by acting on the "primary" environmental variables (e.g., temperature) at the local scale; for Atlantic salmon, spatial coherence of marine survival suggests that broad-scale forcing functions play an important role (Friedland et al. 2000). At the species level, relationships exist between regional survival and single environmental variables (Nickelson 1986; Cole 2000) or linear combinations of the variables (Koslow et al. 2001), but it has been difficult to discern the mechanisms involved. Fewer studies have explored how environmental variables affect salmon size and survival at even finer temporal and spatial scales that affect individual stocks or river systems (Coronado and Hilborn 1998; Ryding and Skalski 1999). The broad latitudinal ranges of many salmon species subject the young stages to different ocean conditions, and some populations also inhabit different ocean areas in the adult stages (Myers et al. 1996). Indeed for some species, long-term inverse patterns of production have been observed between the northern and southern ends of their geographic range (Hare et al. 1999). Although long-term variation in salmon survival and size may be linked to large-scale climatic variation (Ricker 1995; Pyper et al. 1999), it is the shorter-scale variation that is explored here.

Environmental variation also impacts management of economically important marine fisheries like salmon. Unfortunately, management decisions are based largely on predictions from historical stock size and population production characteristics that typically give inadequate weight to variability in environmental conditions. Changes in ocean conditions do affect salmon stocks and disrupt predictions based on population size alone (Francis and Hare 1994; Peterman et al. 1998) and may leave populations vulnerable to overfishing and collapse. Correlation-based analyses of stock dynamics that include environmental data have provided important inferences to guide research, but an understanding of mechanistic relationships is needed to provide better overall predictions as part of management and recovery strategies (Tyler 1992). Examination of environmental factors that may influence production in the nearshore ocean should be a priority for research on the ocean phase of salmon life (Brodeur et al. 2000). Understanding the role of variation in the nearshore ocean with salmon survival will lead to more efficient management, including matching of expensive artificial production to the carrying capacity of the nearshore ocean, replenishment of natural stocks, and setting appropriate escapement for salmon fisheries (Bradford et al. 2000; Welch et al. 2000).

The belief that nearshore ocean dynamics are important influences on salmon survival (Pearcy 1992; Gargett 1997) is supported by $(i)$ correlation between salmon survival and various nearshore environmental variables (e.g., Nickelson 1986); (ii) coherence in survival of stocks in the same region (Beamish et al. 1997; Peterman et al. 1998); and (iii) common survival patterns in the same year for different year classes (Pearcy 1992; Weitkamp et al. 1995). Furthermore, many of these previous studies suggest that most variance in survival occurs in the first 6 months of ocean life; however, the influence of the environment at the time when salmon return to spawn has rarely been considered. Mechanisms through which environmental variability affects salmon survival and size include principally predation, starvation, and impacts on growth rate (Pearcy 1992). However, the nature of most of these linkages is speculative because of the lack of adequate field data.

Coho salmon (Oncorhynchus kisutch) have a broad geographic range along the west coast of North America, appear to be particularly sensitive to environmental conditions, and have a relatively simple 3-year life cycle (Sandercock 1991; Pearcy 1992). They are thus suitable for the exploration of relationships between nearshore ocean conditions and two of the components of production, survival and size. Wild juveniles remain in freshwater for up to 15 months and then migrate to the ocean as smolts. Despite some regional variation, most coho salmon return to spawn in their natal streams after 18 months in the ocean, with a smaller fraction of precocious males (jacks) returning after only 6 months of ocean residence (Sandercock 1991; Weitkamp et al. 1995; Coronado and Hilborn 1998).

In this paper, we first apply cluster analyses to identify the regions of the west coast of North America having coherent patterns in survival and final size of hatchery-released coho salmon, indicating common effects of the marine environment. Then, within each region, the variance in survival and final size of individual releases was evaluated with respect to environmental variability at time and space scales appropriately tailored to the release and return periods. Finally, we evaluate the most important environmental variables affecting coho survival and size in each region and speculate on mechanisms that link these variables to coho salmon.

\section{Methods}

\section{Biological data}

Survival and size data from coded wire tag (CWT) hatchery fish were used. This minimizes the variation resulting from freshwater conditions as in-river residence time is short and barriers to migration are limited or nonexistent. Restricting analyses to releases from hatcheries close to the mouth of the river may further reduce the time for the freshwater portion of the life cycle to influence survival. Patterns of survival derived from hatchery fish may match or track survival patterns of wild salmon (Koslow et al. 2001), although hatchery practices and conditions may also result in lower overall survival than for wild fish (Weitkamp et al. 1995). Some CWT are applied to wild smolts, but these data are extremely limited and would not allow extensive analyses over the desired spatial and temporal scales. Hence, this analysis is limited to using hatchery CWT data to explore the relationship between environmental conditions and salmon production.

Biological data on hatchery CWT coho salmon released between 1973 and 1998 were obtained from the Pacific States Marine Fisheries Commission Regional Mark Information Center (see Johnson (1990) for details and for how survival is calculated). Only data from age-1 nonexperimental normal releases were included in analyses. It is important to note that there have been changes in rearing practices over time and hatchery conditions are not uniform between hatcheries; however, these differences have been ignored in this large-scale analysis. Survival and "returns by year" (catch plus escapement) were summarized for each tag code and the number of jack and adult returns were determined for each release tag code by year and state. Because fewer than $1 \%$ of total coho 
returns occur after more than 2 years at sea (Weitkamp et al. 1995; Coronado and Hilborn 1998), standardizing survival to a single age at recovery was not undertaken. The average survival for each hatchery was then calculated for each year.

Individual fish final size information was also obtained from the CWT database for the same tag codes. Only records that included final length were retained for subsequent size analyses. Initial data processing consisted of converting lengths given as mid-eye fork length to the more commonly listed fork length (FL) using accepted methods (Fleming and Gross 1990). Other measurements were not common enough or had potential conversion errors and were not included. Output from preliminary treatment of the final size data was average final length, standard deviation, and number for each release tag code by year of return and by fishery. The fisheries considered were (i) marine troll, (ii) marine net and seine, (iii) freshwater net and seine, and (iv) hatchery captures. Because each fishery might target fish of different ages and sizes, data from each fishery were kept separate. Differences in final size between sexes were considered by fishery; however, sex was not provided for most records. Preliminary analyses of the limited sex data found differences in size between sexes only for some release groups captured at the hatchery. Because of these preliminary findings and limited data, sex was ignored when calculating the final average size for a release. The average size of fish by age class returning to each hatchery from each release batch was calculated for each year by hatchery for each fishery. Fish spending more than 1 adult year in the ocean were not included in subsequent size analyses owing to limited data for these age classes.

Survival was standardized for each hatchery, whereas jack size and adult size data were standardized by each hatchery and fishery combination ((value - mean)/standard deviation). Standardizing the final size of fish captured in each fishery allowed the final size data for adults and jacks to be combined into a single-size data set for each period. We did not account for changes in fishing regulations that may have influenced the size of fish captured within single fisheries (e.g., Ricker 1995), but standardization does allow data from fish captured in different fishery seasons to be combined. Data sets were created for two periods because cluster formation may be sensitive to hatcheries with limited data. The first set was from hatcheries that had more than 9 years of data for the full period (1973-1998), and the second set included hatcheries with more than 9 years of data for a shorter period of 1980-1994. This meant that all hatcheries in the second data set had at least five common years. Creating two data sets allowed a measure of quality control. If cluster results from both were similar, then the larger data set could be used in subsequent analyses.

The geographic coordinates for each hatchery that released coho are not provided in the CWT database. Hatchery locations and the ocean-entry coordinates for the river mouth on which each hatchery was located were compiled from a variety of sources (L. Weitkamp, NOAA-NMFS, 2725 Montlake Blvd. E, Seattle, WA 98112, personal communication). In this study, releases of fish were assumed to take place at or close to the hatchery location (experimental releases, where fish may have been transported to another location, were not included). Linear hatchery - ocean-entry distances were computed and used as an estimate of the distance upstream that fish were released. This subsequently allowed selection of releases made within a maximum distance from the coast, which minimized the period of time that the smolts were migrating in freshwater and hence the influence of freshwater conditions on size and survival patterns (see Solazzi et al. 1991).

\section{Cluster analysis}

Cluster analysis was undertaken to identify groups of hatcheries (i.e., geographic regions) with similar annual survival or size patterns for each data set. The standardized size and survival data were used to generate clusters using the $k$-means method (SYSTAT
5.0, SPSS Inc., Chicago, Ill.) This clustering method is nonhierarchical and the number of clusters to be found must be specified. Two to eight clusters were generated for each data set. Comparison of the geographically meaningful cluster patterns for each data set allowed regions with similar patterns of final size and survival to be identified.

In addition to identifying regions with different patterns, cluster analyses also revealed the years $t$ in which the clusters were statistically distinct via an analysis of variance style test. Temporal trends in the standardized data for each cluster were investigated using regression analysis. In all statistical tests, significance was defined as $\alpha<0.05$.

The releases in each region identified by the cluster analysis were processed to select portions for further analyses with respect to environmental data. Data subsets were defined to include only releases $(i)$ from hatcheries less than $100 \mathrm{~km}$ inland from the coast, (ii) occurring over less than a 10-day period, and (iii) with more than 10000 fish.

\section{Environmental data}

Lack of understanding about causal mechanisms that produce the observed biological variance often leads to speculative consideration of variables, guided by knowledge of the system, biology of the component parts, and data availability. Six environmental variables that might influence coho salmon survival and final size were chosen to match the temporal resolution in the individual release data. We specifically chose variables used previously in studies of recruitment in marine fish, including three derived from wind (wind speed, upwelling, and cube of wind speed), two measured parameters (sea level, sea surface temperature (SST)), and a derived index of mixed-layer depth. The coast was divided into adjacent $1^{\circ}$ latitude $\times 1^{\circ}$ longitude boxes (hereafter referred to as $1^{\circ}$ boxes), and daily environmental averages for the period of 1970-1998 were obtained for each box (Fig. 1).

Average daily wind speed was calculated from the National Centers for Environmental Prediction (NCEP) surface wind data for each $1^{\circ}$ box (NCEP reanalysis data were provided by the NOAA-CIRES Climate Diagnosis Center, Boulder, Colo., http://www.cdc.noaa.gov/). The daily averages were an average of six hourly data points on a $2.5^{\circ}$ grid. East-west $(u)$ and northsouth $(v)$ components of the wind were interpolated to the center of each $1^{\circ}$ box before computing the wind speed. The alongshore $(v$ wind) component was used in analyses.

The offshore component of Ekman transport provides a proxy for upwelling (Bakun 1973). Average daily cross-shelf upwelling for the midpoint of each $1^{\circ}$ box was calculated from the geostrophic winds derived from surface atmospheric pressure fields at Pacific Fisheries Environmental Laboratory (NOAA; data available at http://www.pfeg.noaa.gov/products/las.html).

The wind imparts energy to the ocean surface proportionally to the cube of wind speed, which is thus a potential index of turbulence. Average daily cubed wind speed ((wind speed $\left.)^{3}\right)$ was calculated from the wind speed for each $1^{\circ}$ box using the NCEP data.

Sea level at the coast is often used as a measure of alongshore transport (Reid and Mantyla 1976; Strub et al. 1987). When transport to the south is high along the coast of North America, coastal sea level is low, and conversely, when transport to the north is high, so is sea level. Adjusted sea level data from the University of Hawaii Sea Level Center (http://www.soest.hawaii.edu/kilonsky/ uhslc.html) were available for seven sites along the west coast of North America for the time period considered. Data were standardized for each station and converted to daily anomalies.

Temperature has often been assumed to be the most important environmental variable affecting biological processes. Average daily SST for each $1^{\circ}$ box was obtained from the Comprehensive Ocean Atmosphere Data Set (Mendelssohn and Roy 1996). These data comprise real observations from ships and buoys. For this study, we 
Fig. 1. Map of west coast of North America with the center of each $1^{\circ}$ box $(n=32)$ indicated by a plus $(+)$. The locations of the seven named sea level stations are indicated by the solid circles. The locations of the river mouths of the hatcheries releasing coded wire tagged coho salmon (Oncorhynchus kisutch) between 1973 and 1998 in each cluster are shown by stars $(n=225)$. The shaded Puget Sound - Strait of Georgia region is expanded in the lower inset map to show the boundary between cluster 2 and cluster 3 . The upper inset map is of the west coast of North America with the study area shaded.

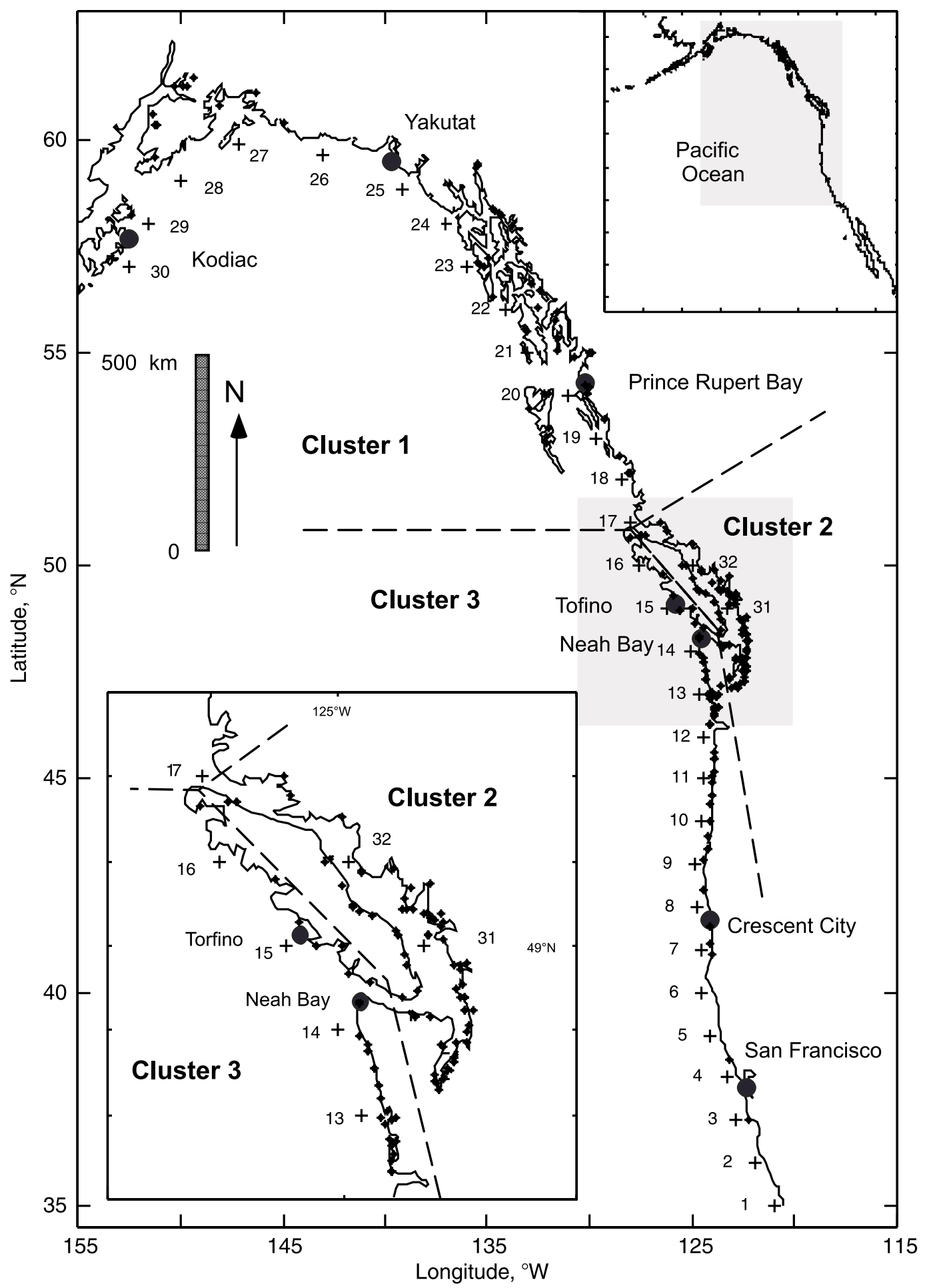

also used a derivative of subsurface temperature structure that we refer to as mixed-layer depth (MLD), which is a function of mixing energy and buoyancy input and refers to the zone of relatively homogeneous water formed by the history of mixing. Temperature has often been used to define the MLD, in part owing to the scarcity of salinity data and the ease of measurement reliability (Brainerd and Gregg 1995). In regions of relatively high freshwater input or seasonally variable salinity, this value may not represent the true MLD, but the seasonal thermocline is still a good measure of MLD (Brainerd and Gregg 1995). MLD was calculated from casts ar- 
chived in the World Ocean Database 98 Standard Level Temperature Profiles (Levitus et al. 1998). The individual temperature-depth observations in each $1^{\circ}$ box were averaged to provide daily temperaturedepth estimates. Only casts to depths greater than $100 \mathrm{~m}$ were included to remove shallow and nearshore casts where the MLD is often poorly resolved. MLD was defined as the depth $(z)$ where the change in temperature $(T)$ was most rapid, i.e., $\mathrm{d} T / \mathrm{d} z$ was maximum. There is a correlation between MLD calculated from density data and the thermocline depth at Vancouver Island (G.W. Boehlert, unpublished data), supporting the use of this variable as a proxy for MLD. It is acknowledged that this measure of MLD may be less precise in the northern regions of this study, but it represents a useful proxy of subsurface structure related to MLD available for retrospective analyses of the kind performed here.

\section{Matching biological and environmental data}

The biological response variables considered within each cluster were survival, jack size from fish recaptured at the hatchery, and adult size of fish captured in the nearshore troll fishery. Restricting the environmental analyses to a single fishery allowed the actual size of fish to be used. Variation in these response variables attributable to environmental predictor variables was examined for three time periods. The first varied temporally and was specifically tailored to each individual hatchery release group. The time period began 10 days before and ended 30 days after the mean release day (some releases took place over 10 days). The second period considered was the 3 months when most jacks were returning to coastal waters close to the release region (July 1 - October 1 in the release year). The third time period was the 3 months when most adults were returning to coastal waters close to the release region (July 1 - October 1, year after release year). The peak time of adult coho salmon return varies from September to January, depending on the stock (Weitkamp et al. 1995), and so these time periods were chosen to include at least some marine residence time for all populations of returning jacks and adults.

For each time period, the environmental predictor variables were integrated in four different ways. The first measure was the mean value of the environmental variable. The second was the proportion of days in which an event greater than a threshold value occurred (i.e., upwelling $>0$, standardized sea level $>0, v$ wind $>0$ (northward event), SST $>12^{\circ} \mathrm{C}$, (wind speed) $)^{3}>125 \mathrm{~m}^{3} \cdot \mathrm{s}^{-3}$, and MLD > $30 \mathrm{~m}$ deep). The third and fourth measures were the cumulative sum of events greater (positive) and less (negative) than the same threshold values. For example, the positive sum of MLD was the sum of all daily MLD that were deeper than $30 \mathrm{~m}$ in the period of time considered. A large sum indicates a deep MLD over the time considered, whereas a small sum indicates a relatively shallow MLD. The use of positive and negative does not imply any predicted positive or negative effects on salmon but rather is used to approximately divide the range of environmental data in half.

Environmental conditions for each release period were calculated using the data from the $1^{\circ}$ box closest to the release river mouth location. At this time, salmon are known to be in the release region. Environmental conditions at the time when jacks were returning were the daily average of the three closest $1^{\circ}$ boxes to the release river. Environmental conditions at the time when adults were returning were created from the daily average from the five closest $1^{\circ}$ coastal boxes to the release river mouth. The increasing spatial region over which environmental conditions were averaged reflects the relative uncertainty in the location of the returning jack and adult coho salmon.

The mean and proportion measures were calculated using the days for which environmental data existed in the time period considered. The cumulative positive and negative sums were calculated using the available data for the period of time being considered, with missing days being replaced by the mean for the period. If no environmental data existed for that release period, then the release was excluded during analysis using that variable.

\section{Models}

Preliminary exploration and analyses of these data via linear models often produced significant relationships but with very little variance in the response variable being explained by the predictor variable (most $R^{2}<10 \%$ ). Scatterplots showed that many of the univariate relationships had nonlinear responses to the predictor variables. Multiple linear regression models were also attempted; again, although highly significant models were obtained, the variance explained by these models was generally less than $20 \%$. Linear models relating size and survival to the environmental conditions will not be addressed further in this manuscript. Release weight was always significantly related to size and survival and was used in subsequent models.

Relationships between environmental and biological variables are often nonlinear (Cury and Roy 1989; Cury et al. 1995); however, present knowledge of the relationships does not always allow prediction of the form. For this reason, methods using the data to estimate the appropriate relationship are desirable. Iterative algorithms that extend linear multiple regression analysis to generalized additive models (GAM) have been used in several fisheries studies (Cury and Roy 1989; Cury et al. 1995). These methods, involving empirically estimated transformations of the data, provide a method for exploring the relationship between response and predictor variables when the form is unknown (Cury et al. 1995).

Analyses with nonlinear multiple regression models were used to explore the relationship between the response variables (size and survival) and the predictor variables (release weight and the nearshore environmental conditions) using the alternating conditional expectation (ACE) algorithm (Breiman and Freidman 1985; Cury and Roy 1989; Cury et al. 1995). ACE algorithms are iterative and allow transformations of both response and predictor variables. The partial residuals from the existing transformations of response and predictor variable relationships are calculated and transformations for the new variables are found.

Each of the three response variables (survival, jack size, and adult size) was modeled in each of the three possible time periods (release, jack return, adult return). This resulted in examination of eight general models (the influence of conditions on jack size in the adult year is nonsensical). To explore the relationships, each of the six environmental variables (calculated in four ways) was examined together with the release weight of fish for the eight models for each of the three regions found in the earlier cluster analyses. This resulted in $6 \times 4 \times 8 \times 3=576$ models of the form

$$
\begin{aligned}
& \text { Response }_{\text {transformed }}=\text { release weight } \\
&+ \text { envinsformed } \\
& \text { envental variable } \\
& \text { transformed }
\end{aligned}
$$

These models were examined for patterns in how and which environmental variables (including how they were measured) explained variance in the response variables in each of the three time periods and regions identified. "Best" models were selected by the simple criterion of maximum $R^{2}$ values. The relationships for environmental transformations were approximated with second-order polynomials, and these indicate the relationship between the particular environmental and response variables.

\section{Results}

A quality-controlled data set of 4382 releases of age-1 coho salmon made from 225 hatcheries for the years from 1973 to 1998 was obtained. Final size was obtained for 960689 fish captured in the four fisheries. Most fish with size information were captured as adults after 1 year in the 
ocean $(92.6 \%)$, with $4.2 \%$ captured as jacks. The remaining sizes were from fish returning in subsequent years and were not considered. A single release could have individual fish recaptured in all four fisheries; thus, there were 19379 average return sizes calculated for the 4382 total releases.

\section{Cluster analyses and spatial patterns in size and survival}

The number of meaningful clusters found for each data set examined was either one or three (Table 1). Survival and adult size both produced three clusters, whereas the smaller data sets of jack size did not lead to any geographically meaningful clusters. The geographic identity and number of clusters identified for the two time periods (1973-1998 and 1980-1994) were the same. Geographic boundaries between clusters were obvious from the output and were the same for survival and adult size. Three geographically distinct clusters were created from these similar results. All hatcheries, including those with fewer than 9 years of data, were allocated to one of the three cluster regions according to the geographic location of the river entering the ocean (Fig. 1). The break between the northern (1) and other clusters (2 and $3)$ was at the northern end of Vancouver Island $\left(51.5^{\circ} \mathrm{N}\right)$. The Puget Sound - Strait of Georgia cluster (2) included all hatcheries in the Strait of Georgia and Puget Sound between the northern tip of Vancouver Island and Neah Bay, Washington (WA), at $48.5^{\circ} \mathrm{N}$. Cluster 3 was hatcheries from the northern tip of Vancouver Island to California. An average of $71 \%$ of hatcheries originally in the northern cluster (cluster 1), $84 \%$ originally in Puget Sound - Strait of Georgia (cluster 2), and $96 \%$ originally in the south (cluster 3 ) remained in the same cluster after geographic realignment. The final clusters consisted of 51 hatcheries in cluster 1 (1140 releases), 93 in cluster 2 (1559 releases), and 81 in cluster 3 (1683 releases) (Fig. 1).

The distinctness of the clusters differed between years for both jack and adult size and survival. Standardized jack size was almost never different between regions, as expected from the lack of geographic pattern in the jack size cluster analysis. Adult size and survival were distinct between clusters in over half of the years, but not always the same year (Fig. 2). This is consistent with the general lack of correlation among survival, jack size, and adult size; the only significant correlation (positive) occurred between survival and jack size in cluster 2 (Table 2). Significant correlations between clusters were limited to the coastal clusters 1 and 3 . Furthermore, as might be expected, survival in cluster 3 was significantly correlated with survival from the Oregon Production Area (OPI, see Nickelson 1986) during the time period when both were available (1974-1996, $r=0.67$, $p<0.0005)$.

The average standardized survival, jack size, and adult size varied between years (Fig. 2). There was a significant linear decline in survival in releases made in Puget Sound - Strait of Georgia (cluster 2) and an almost significant $(p=0.0515)$ decline in the south (cluster 3 ), whereas in the north (cluster 1 ), there was no significant trend in survival (Table 3 ). Jack size declined significantly through time in cluster 1 , declined nonsignificantly in cluster 2 , and showed no trend in cluster 3. Adult size also declined significantly in cluster 2 but not in the other two regions. In the cases with a significant de- cline, the linear regression (year) explained 19-46\% of the variance in the response variable (Table 3 ).

Comparison of the relationship between survival, jack size, and adult size in each cluster shows they were impacted differently in the same years (Fig. 2). For example, in 1983, jack and adult size, but not survival, were below average in the south. Adult size and survival in the south was also low in 1992. There was little coherence in the other two regions in survival and adult or jack size (Table 2).

\section{Important environmental variables: all models}

All 576 models were initially evaluated to examine $(i)$ the time period most strongly influencing survival and growth on average, (ii) the best method of calculating the environmental variable (mean, positive or negative sum, or proportion), and (iii) the most important environmental variable in the analyses. The metric used for this evaluation was the mean of the $R^{2}$ values for the appropriate subset of the 576 models. For example, to determine the most important time period in cluster 1 , the average of the 24 models (each using one of six environmental variables, calculated four ways) was calculated for each of the three time periods, and the time period with the highest average $R^{2}$ was defined as most important.

This analysis suggested that survival in all three regions was influenced most by environmental conditions at some time after release, not by conditions at the time of release (Table 4). Models with survival as the response variable explained most variance when environmental variables from the time when jacks were returning (July-October, release year) were used in clusters 2 and 3, whereas in the northern cluster, environmental conditions when adults were returning (July-October, following year) explained more variance in survival. Comparing between clusters, survival was influenced most by environmental conditions in the south, then in the north, and least in the Puget Sound region. Jack size was most influenced by environmental conditions at the time of jack return in the south (cluster 3 ) and by conditions during release in cluster 2, whereas in the north, the same amount of variance was explained in both periods. Models for cluster 1 explained more variance in jack size than in the other clusters. Adult size was related most to environmental conditions at times after release, in the adult return period in cluster 2 and in the jack period in clusters 1 and 3. As for survival, models in cluster 3 explained the most variance in adult size (Table 4).

In a similar way, the most variance in the response variables was explained by models using environmental variables calculated as the sum of positive or negative events, rather than by using the mean, or proportion of days above a threshold value (Table 5). This suggests that it is the sum of conditions above or below a threshold experienced over a period of time that influence salmon size and survival, rather than mean conditions.

The most important environmental variable as indicated by the highest average amount of variance explained using all of the nonlinear models was MLD (Table 6). In eight of the nine cases, models using MLD explained on average more variance than the other environmental variables. For survival and jack and adult size, models incorporating variation in MLD explained most variance in clusters 1 and 3 and 
Table 1. Maximum number of geographically meaningful clusters formed from analyses of the coho salmon (Oncorhynchus kisutch) releases.

\begin{tabular}{|c|c|c|}
\hline Data set & $\begin{array}{l}\text { No. of hatcheries } \\
\text { (no. of hatchery } \\
\text { years) }\end{array}$ & $\begin{array}{l}\text { No. of } \\
\text { clusters } \\
\text { identified }\end{array}$ \\
\hline \multicolumn{3}{|l|}{ Survival clusters } \\
\hline$\%$ survival, all hatcheries & 225 (1716) & NA \\
\hline \% survival, 1980-1994 & $54(653)$ & 3 \\
\hline \% survival, 1973-1998 & $76(1120)$ & 3 \\
\hline \multicolumn{3}{|l|}{ Adult size clusters } \\
\hline Adult, all fisheries & $186(1577)$ & NA \\
\hline Adult, all fisheries, 1980-1994 & $47(560)$ & 3 \\
\hline Adult, all fisheries, 1973-1998 & $73(1037)$ & 3 \\
\hline \multicolumn{3}{|l|}{ Jack size clusters } \\
\hline Jack, all fisheries & $118(842)$ & NA \\
\hline Jack, all fisheries, 1980-1994 & $23(259)$ & 1 \\
\hline Jack, all fisheries, 1973-1998 & $37(473)$ & 1 \\
\hline \multicolumn{3}{|c|}{$\begin{array}{l}\text { Note: The number of clusters is reported as } 1 \text { if no geographically } \\
\text { meaningful clusters were found. The number of hatcheries and total years of } \\
\text { release or final size data available before selection of hatcheries with more } \\
\text { than } 9 \text { years data for either time period is shown. Hatcheries with just a } \\
\text { single year of data could not be standardized, and so the number of } \\
\text { standardized hatcheries was less than the total number. NA, not applicable. }\end{array}$} \\
\hline
\end{tabular}

least in cluster 2. Sea level was most important in influencing survival in cluster 2 and was also the second most important variable in the other regions. Least variance was explained in cluster 2 for all environmental variables.

\section{Important environmental variables: best models}

Although the analyses of the average model values indicate general patterns, they do not reveal the relationship between the response variables and the environmental variables. To do this, the best nonlinear additive models (highest $R^{2}$ ) that used more than 50 observations were chosen for the eight general models in each of the three clusters $(n=24$ best models). The most common method of calculating the environmental variable was the sum of positive $(n=14)$ or negative $(n=7)$ daily events in the period of time considered. The mean value was used in two models, whereas the proportion of days above the positive value was used as the method of calculation in only one of the 24 best models. Thus, in the final consideration of the best models, only the best models that used the sum of positive or negative conditions were used, i.e., the three best models that used the mean or proportion were replaced with the next best model that used the positive or negative daily sum. After this adjustment, positive daily sum models accounted for 17 of 24 models.

These 24 best nonlinear models in the three regions had a mean $R^{2}=0.60$ and were based on an average of 201 releases and 18 years of releases. The best models differed with regard to the most important time period for variability in size and survival compared with the analysis of the average values for all the models. In the north (cluster 1), the model incorporating environmental conditions at the time of return explained more variance in survival than the other time periods (Fig. 3c). Survival had most variability explained by models using environmental conditions at the time of release in the Puget Sound (Fig. 4a) and southern regions (Fig. 5a). Overall, the survival models with highest $R^{2}$ were found in cluster 3 followed by cluster 1 . The most important time period for explaining variance in jack size was less clear. In the northern and southern regions, both time periods explained equal variance (Figs. $3 d$ and $3 e$, Figs. $5 d$ and 5e), whereas in the central cluster (Puget Sound - Strait of Georgia), the model incorporating the conditions at the time of jack return explained more variance in jack size (Fig. 4e). As for survival models, models in clusters 1 and 3 best explained variance in jack size. Variation in adult size was explained best by the models incorporating environmental conditions at the time of release in all three regions (Figs. $3 f, 4 f, 5 f$ ), with cluster 3 better than cluster 1 better than cluster 2 .

The most important environmental variable in each best model was similar for all clusters. MLD was the most important variable in four of eight best models in all three clusters, whereas sea level was chosen in one model in cluster 1, four models in cluster 2, and three models in cluster 3. SST was chosen twice in cluster 1 and once in cluster 3 , and (wind speed) ${ }^{3}$ was chosen once in cluster 1 . None of the other variables was ever used in the best models.

The transformations for each best model in the most important time period show the nature of the relationship between the environmental variable and each response variable. These relationships were approximated with a second-order polynomial as an indication of the shape, and these explained an average of $41 \%$ of the transformation variance. In cluster 1 , survival decreased as the sum of daily MLD less than $30 \mathrm{~m}$ increased (Fig. 3c). Jack size decreased with increasing sum of daily negative (wind speed) ${ }^{3}$ (daily (wind speed) ${ }^{3}<125 \mathrm{~m}^{3} \cdot \mathrm{s}^{-3}$ ) at the time of release (Fig. $3 d$ ). At the time of jack return, jack size at first declined with increasing positive sea level and then increased (Fig. 3e). Adult size increased with increasing sum of daily values of SST $>12^{\circ} \mathrm{C}$ at the time of release (Fig. 3f).

In cluster 2, although a different time period was more important, a decrease in survival was also associated with an increase in the sum of the daily MLD when depth was below $30 \mathrm{~m}$ at the time when smolts first entered the ocean (Fig. $4 a$ ). Jack size was greatest when the sum of positive daily MLD during the time of return was intermediate (Fig. 4e). Adult size in cluster 2, however, increased as the sum of the MLD when depth was below $30 \mathrm{~m}$ at the time when smolts first entered the ocean increased (Fig. 4f).

In the south (cluster 3), survival also decreased with an increase in the sum of daily MLD below $30 \mathrm{~m}$ at the time of release (Fig. 5a). As mentioned earlier, variance in jack size was explained equally by conditions at the time of release and the time of return. A slight increase in the sum of daily MLD $>30 \mathrm{~m}$ at the time of return was associated with larger jack size (Fig. 5e), whereas an increase in the sum of daily SST $>12^{\circ} \mathrm{C}$ at the time of release was associated with decreased jack size (Fig. 5d). An increase in the sum of daily MLD > $30 \mathrm{~m}$ during the time of release was associated with an increase in adult size in the south.

Inspection of the remaining model relationships at the less important time periods for each response variable shows a range of other relationships. For example, an increase in 
Fig. 2. Average standardized cluster values by year for coho salmon (Oncorhynchus kisutch). (a) Survival cluster averages by release year. Squares represent the northern cluster, diamonds the Puget Sound - Strait of Georgia cluster, and triangles the southern cluster. (b) Jack size cluster averages by return year. Symbols as in $a$. (c) Adult size cluster averages by return year. Symbols as in $a$. The solid portions of the bars at the base of each panel indicate when the annual cluster values were not significantly different, whereas the open bars indicate when the clusters were distinct (via analysis of variance).
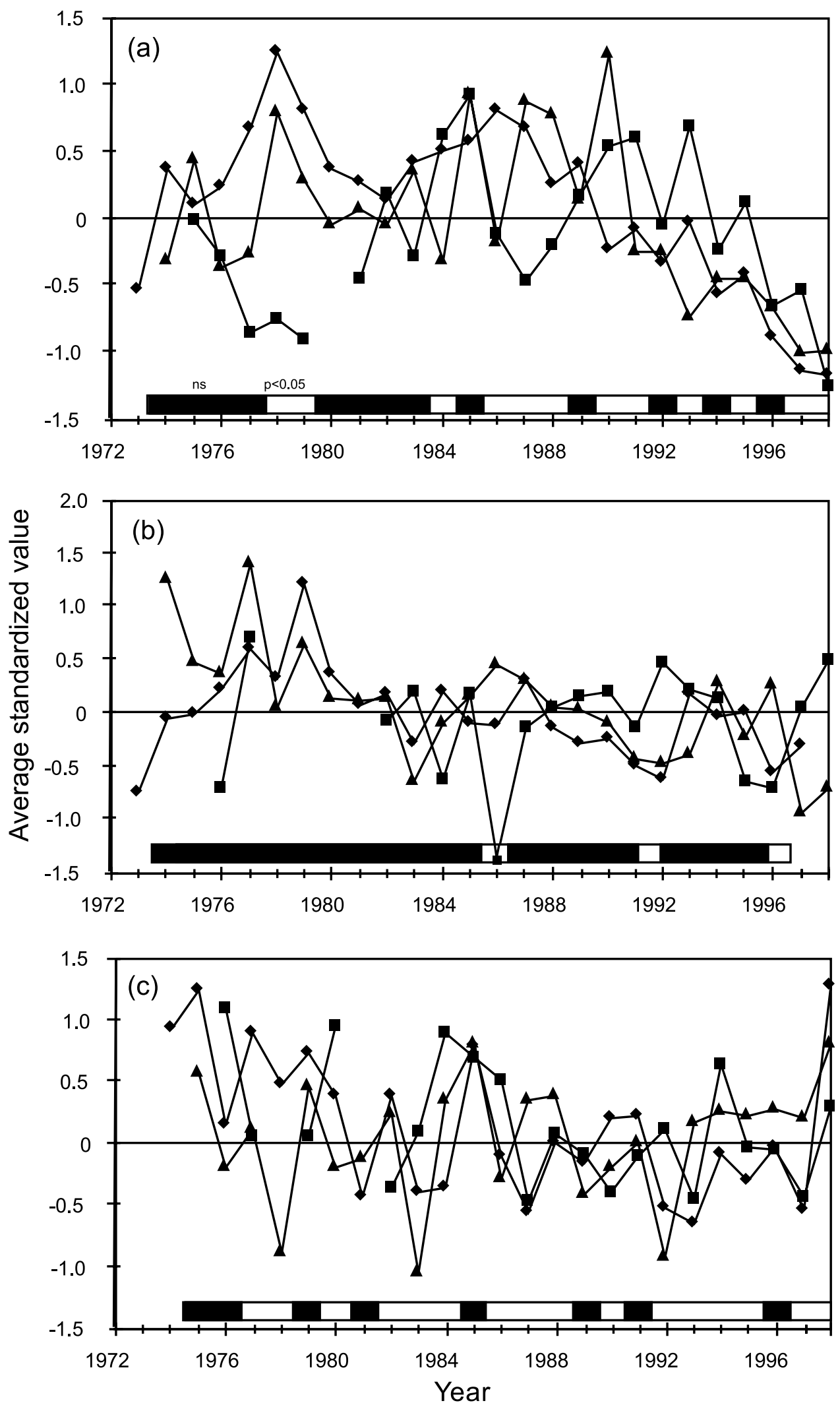
Table 2. Correlation coefficients (Pearson's $r$ ) between annual values of survival, jack size, and adult size within and between clusters for coho salmon (Oncorhynchus kisutch).

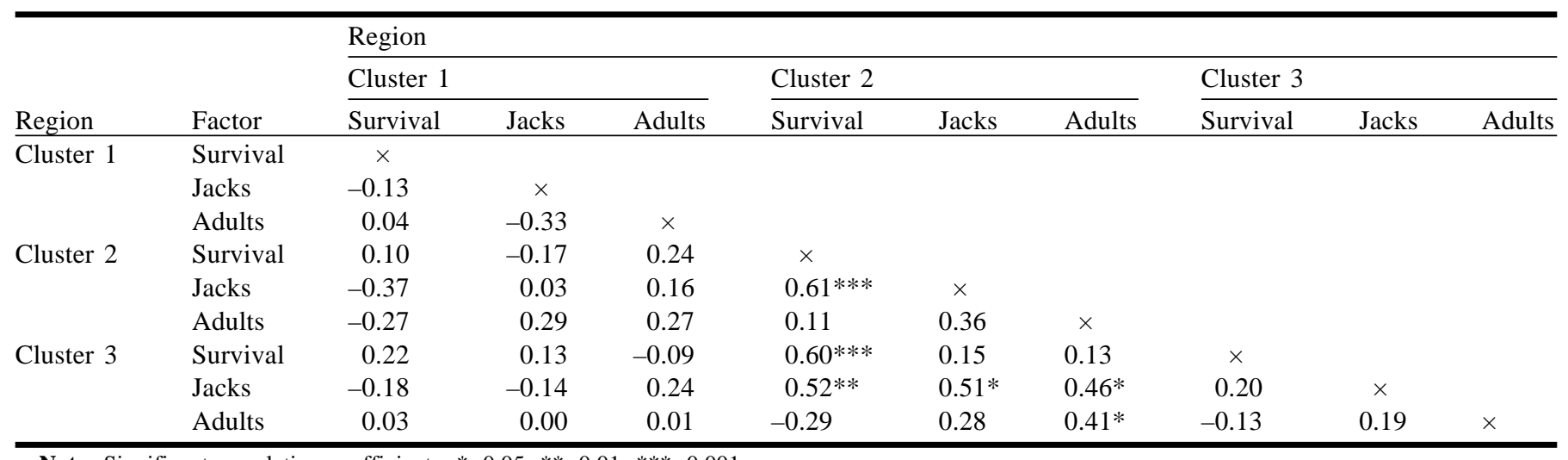

Note: Significant correlation coefficients: *, 0.05; **, $0.01 ; * * *, 0.001$.

Table 3. Results from linear regressions on annual average standardized survival and jack and adult size through time in each cluster for coho salmon (Oncorhynchus kisutch).

\begin{tabular}{llllll}
\hline Relationship & df & Slope & $F$ statistic & $p$ & $R^{2}$ \\
\hline Survival & & & & & \\
Cluster 1 & 22 & 0.0061 & 0.1211 & 0.7313 & 0.0057 \\
Cluster 2 & 25 & -0.501 & 15.601 & $\mathbf{0 . 0 0 0 6}$ & 0.394 \\
Cluster 3 & 24 & -0.0322 & 4.2184 & 0.0515 & 0.155 \\
Jack size & & & & \\
Cluster 1 & 18 & 0.007 & 0.1291 & 0.7237 & 0.0075 \\
Cluster 2 & 25 & -0.0208 & 3.5720 & 0.0715 & 0.133 \\
Cluster 3 & 24 & -0.501 & 19.472 & $\mathbf{0 . 0 0 0 2}$ & 0.4585 \\
Adult size & & & & \\
Cluster 1 & 20 & -0.0294 & 3.7927 & 0.0664 & 0.1664 \\
Cluster 2 & 25 & -0.0347 & 5.5725 & $\mathbf{0 . 0 2 7 1}$ & 0.1950 \\
Cluster 3 & 23 & 0.0121 & 0.671 & 0.4215 & 0.0296 \\
\hline
\end{tabular}

Note: Significant $p$ values are shown in bold font.

Table 4. Most important time period for calculating the environmental variables using all of the nonlinear models for coho salmon (Oncorhynchus kisutch).

\begin{tabular}{lllll}
\hline Response variable & Time period & Cluster 1 (North) & Cluster 2 (Puget) & Cluster 3 (South) \\
\hline Survival & Release & $0.331(471)$ & $0.217(698)$ & $0.330(254)$ \\
& Jack & $0.357(517)$ & $\mathbf{0 . 3 0 6}(741)$ & $\mathbf{0 . 4 4 3}(272)$ \\
\multirow{2}{*}{ Jack size } & Adult & $\mathbf{0 . 3 9 5}(507)$ & $0.304(732)$ & $0.425(272)$ \\
& Release & $\mathbf{0 . 6 9 1}(75)$ & $\mathbf{0 . 3 2 9}(135)$ & $0.488(143)$ \\
Adult size & Jack & $\mathbf{0 . 6 9 1}(78)$ & $0.323(142)$ & $\mathbf{0 . 5 2 4}(153)$ \\
& Adult period & NA & NA & NA \\
& Release & $0.408(436)$ & $0.185(661)$ & $0.410(230)$ \\
& Jack & $\mathbf{0 . 4 1 6}(480)$ & $0.216(704)$ & $\mathbf{0 . 4 7 1}(247)$ \\
& Adult & $0.383(468)$ & $\mathbf{0 . 2 2 6}(702)$ & $0.442(249)$ \\
\hline
\end{tabular}

Note: The most important period in each cluster is indicated by the highest mean $R^{2}$ for the three cells (bold type). The mean $R^{2}$ (and number of observations per model) in each cell was calculated from the 24 models for each time period and response variable combination in each cluster. Each model in the group used a different environmental variable calculated in one of four possible ways. NA, not applicable.

negative sea level sums (i.e., lower sea level) was associated with increased adult size in the south (Figs. $5 g$ and $5 h$ ).

\section{Release weight and size and survival}

The transformation relationships (graphs for these transformations are available on request) for release weight indicate that in the north (cluster 1) survival increased with an increase in release weight, whereas in the southern and
Puget Sound clusters survival first declined as release weight approached about $30 \mathrm{~g}$ and then increased. There is a difference in the weight of fish released, with smaller fish being released in the north. Jack size increases with increasing release weight up to about $40 \mathrm{~g}$ in all three regions. In clusters 2 and 3, where larger smolts were released, jack size then declines as release weight increases above about $50 \mathrm{~g}$. Adult size increases with release weight in all three regions, 
Table 5. Most important method of calculating the environmental variables using all of the nonlinear models for coho salmon (Oncorhynchus kisutch).

\begin{tabular}{lllll}
\hline Response variable & Method & Cluster 1 (North) & Cluster 2 (Puget) & Cluster 3 (South) \\
\hline Survival & Mean & $0.357(512)$ & $0.276(745)$ & $0.398(275)$ \\
& Negative & $0.361(491)$ & $\mathbf{0 . 2 9 2}(710)$ & $\mathbf{0 . 4 1 8}(261)$ \\
& Positive & $\mathbf{0 . 4 1 0}(479)$ & $0.288(693)$ & $0.403(254$ \\
Jack size & Proportion & $0.316(512)$ & $0.248(745)$ & $0.378(275)$ \\
& Mean & $0.711(75)$ & $0.291(143)$ & $0.526(153)$ \\
& Negative & $0.706(72)$ & $0.345(137)$ & $0.499(145)$ \\
Adult size & Positive & $\mathbf{0 . 7 1 6}(79)$ & $\mathbf{0 . 3 6 8}(132)$ & $\mathbf{0 . 5 4 0}(141)$ \\
& Proportion & $0.630(81)$ & $0.299(143)$ & $0.458(153)$ \\
& Mean & $0.386(474)$ & $0.208(711)$ & $0.454(250)$ \\
& Negative & $0.419(455)$ & $0.220(676$ & $0.453(238)$ \\
& Positive & $\mathbf{0 . 4 2 6}(443)$ & $\mathbf{0 . 2 2 5}(659)$ & $\mathbf{0 . 4 5 7}(230)$ \\
& Proportion & $0.381(474)$ & $0.183(711)$ & $0.400(250$ \\
\hline
\end{tabular}

Note: The most important method for each response variable in each cluster is indicated by the highest mean $R^{2}$ for the set of four cells (bold type). The mean $R^{2}$ (and number of observations per model) in each cell was calculated from the 18 (12 for jacks) models for the environmental and response variable combination in each cluster. Each model in the group used a different environmental variable calculated in three (two for jacks) different time periods.

Table 6. Most important environmental variable using all the nonlinear models for coho salmon (Oncorhynchus kisutch).

\begin{tabular}{|c|c|c|c|c|}
\hline Response variable & Environmental variable & Cluster 1 (North) & Cluster 2 (Puget) & Cluster 3 (South) \\
\hline \multirow[t]{6}{*}{ Survival } & MLD & $0.559(121)$ & $0.324(524)$ & $0.482(185)$ \\
\hline & Sea level & $0.377(548)$ & $\mathbf{0 . 3 5 3}(649)$ & $0.457(262)$ \\
\hline & $v$ wind & $0.271(653)$ & $0.259(840)$ & $0.386(299)$ \\
\hline & $(\text { Wind speed })^{3}$ & $0.268(653)$ & $0.242(840)$ & $0.373(299)$ \\
\hline & Upwelling & $0.329(571)$ & $0.239(777)$ & $0.359(285)$ \\
\hline & SST & $0.361(446)$ & $0.239(710)$ & $0.338(267)$ \\
\hline \multirow[t]{6}{*}{ Jack size } & MLD & $0.741(18)$ & $0.446(86)$ & $\mathbf{0 . 5 9 0}(94)$ \\
\hline & Sea level & $0.712(84)$ & $0.409(122)$ & $0.509(145)$ \\
\hline & $v$ wind & $0.655(91)$ & $0.29(167)$ & $0.446(169)$ \\
\hline & $(\text { Wind speed })^{3}$ & $0.716(91)$ & $0.258(167)$ & $0.446(169)$ \\
\hline & SST & $0.641(67)$ & $0.295(138)$ & $0.556(151)$ \\
\hline & Upwelling & $0.699(87)$ & $0.257(153)$ & $0.488(161)$ \\
\hline \multirow[t]{6}{*}{ Adult size } & MLD & 0.644 (114) & $\mathbf{0 . 2 5 7}(520)$ & 0.522 \\
\hline & Sea level & $0.375(501)$ & $0.222(620)$ & $0.491(234)$ \\
\hline & $v$ wind & $0.324(607)$ & $0.210(770)$ & $0.416(268)$ \\
\hline & $(\text { Wind speed })^{3}$ & $0.329(607)$ & $0.175(770)$ & $0.347(268)$ \\
\hline & SST & $0.403(411)$ & $0.205(705)$ & $0.416(248)$ \\
\hline & Upwelling & $0.340(530)$ & $0.185(749)$ & $0.452(260)$ \\
\hline
\end{tabular}

Note: The most important variable in each cluster is indicated by the highest mean $R^{2}$ for the six cells (bold type). The mean $R^{2}$ (and number of observations per model) in each cell was calculated from the 12 ( 8 for jacks) models for the environmental method and response variable combination in each cluster. Each model in the group used a different environmental method calculated in three (two for jacks) different time periods. Abbreviations are MLD (mixed-layer depth) and SST (sea surface temperature).

although at very large release weight in the south, adult size does decline. In general, there is an increase in survival and size with increasing release weight in all regions.

\section{Discussion}

This exploratory analysis of the common patterns in size and survival and the environmental variables that most influence these response variables yielded some important insights into the mechanisms that produce the observed variance. The exploratory nature and methods used to understand these relationships preclude the use of statistical tests to separate between particular effects, instead the relative explanatory power of each model was used as the guide to select the most important patterns.

\section{Spatial and temporal trends in size and survival}

The geographically meaningful clusters formed by the cluster analysis based on survival and adult size identified the same three regions. The break between the northern and southern cluster at the tip of Vancouver Island identified in this study matches the transition between the upwelling and downwelling regions of the west coast, also coinciding with an important boundary between fishery production domains (Ware and McFarlane 1989).

Patterns of jack size did not reveal distinct regions, perhaps because there was insufficient data to resolve the pattern or there is a threshold size for jacks that results in a smaller range of jack sizes. In the latter case, this smaller dynamic range of jack size would make detecting consistent spatial patterns in the cluster analysis more difficult. Adult 
Fig. 3. Cluster 1 (north) environmental variable transformations from the best nonlinear model (highest $R^{2}$ ). The $R^{2}$ for the model, number of observations, and number of years that the observations covered are shown at the top of each panel. The environmental variable and calculation method for each best model is indicated on the $x$ axes. The shape of each transformation relationship indicates the relationship of the environmental variable to each response variable, and these have been approximated with second-order polynomials. The $R^{2}$ for these fitted polynomial relationships is also shown for each panel. The response variable and time period for the environmental variables for each panel are $(a)$ survival, release period; $(b)$ survival, jack return period;. $(c)$ survival, adult return period; $(d)$ jack size, release period; $(e)$ jack size, jack return period; $(f)$ adult size, release period; $(g)$ adult size, jack return period; $(h)$ adult size, adult return period. The relationship between jack size at return and environmental conditions when adults return was not examined, as it had no biological basis.
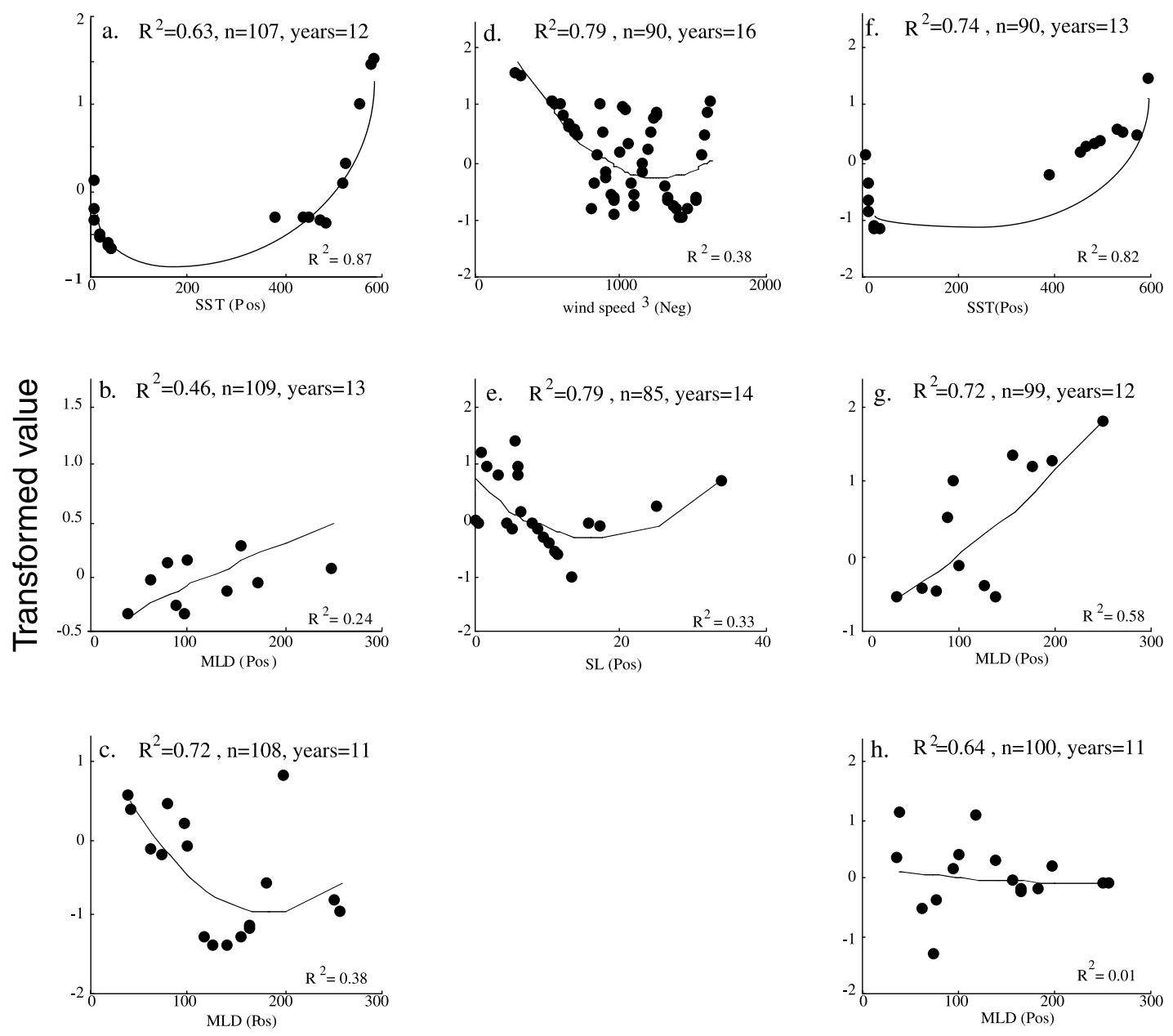

size produced the same clusters as did survival, suggesting commonalities in the regions where the fish are residing during the ocean period of their life cycle. Thus, both adult size and survival are influenced by conditions in the same region, although it is not possible to tell from cluster analysis if common physical factors produced the patterns. Furthermore, the annual patterns of survival, jack size, and adult size in each region showed that different responses occurred in the same year.

The results of the cluster analyses support the a priori division between coastal Washington and Oregon and Puget Sound salmon used in previous studies of survival (e.g., Coronado and Hilborn 1998; Beamish et al. 2000). On the outer coast, the division between clusters 1 and 3 is also consistent with the division in coherence of upwelling favorable winds in summer and with the changes in British Columbia salmonid survival noted by Welch et al. (2000). It is also near the bifurcation of the Subarctic current into the
California and Alaska currents. Interannual differences in either the latitudinal position of this bifurcation or the relative proportion of water entering these two currents might affect salmon ocean survival through effects on prey production or on salmon distribution and migration (Chelton 1984).

The decline in survival of CWT hatchery-released coho in the south (cluster 3) over the last 20 years was similar to that reported elsewhere (e.g., Coronado and Hilborn 1998; Beamish et al. 1999) and has occurred despite large increases in the release of hatchery fish (e.g., Mahnken et al. 1998). Despite possible freshwater and hatchery influences, unfavorable ocean conditions are thought to be largely responsible (Coronado and Hilborn 1998; Mahnken et al. 1998).

\section{Role of environmental variation in size and survival}

Different patterns for size and survival in common regions suggest that the same set of environmental variables may be acting in different ways on the different life stages of coho 
Fig. 4. Cluster 2 (Puget Sound - Strait of Georgia) environmental variable transformations from the best nonlinear model (highest $R^{2}$ ). The $R^{2}$ for the model, number of observations, and number of years that the observations covered are shown at the top of each panel. The environmental variable and calculation method for each best model is indicated on the $x$ axes. The shape of each transformation relationship indicates the relationship of the environmental variable to each response variable, and these have been approximated with second-order polynomials. The $R^{2}$ for these fitted polynomial relationships is also shown for each panel. The response variable and time period for the environmental variables for each panel are $(a)$ survival, release period; $(b)$ survival, jack return period; $(c)$ survival, adult return period; $(d)$ jack size, release period; $(e)$ jack size, jack return period; $(f)$ adult size, release period; $(g)$ adult size, jack return period; $(h)$ adult size, adult return period. The relationship between jack size at return and environmental conditions when adults return was not examined, as it had no biological basis.
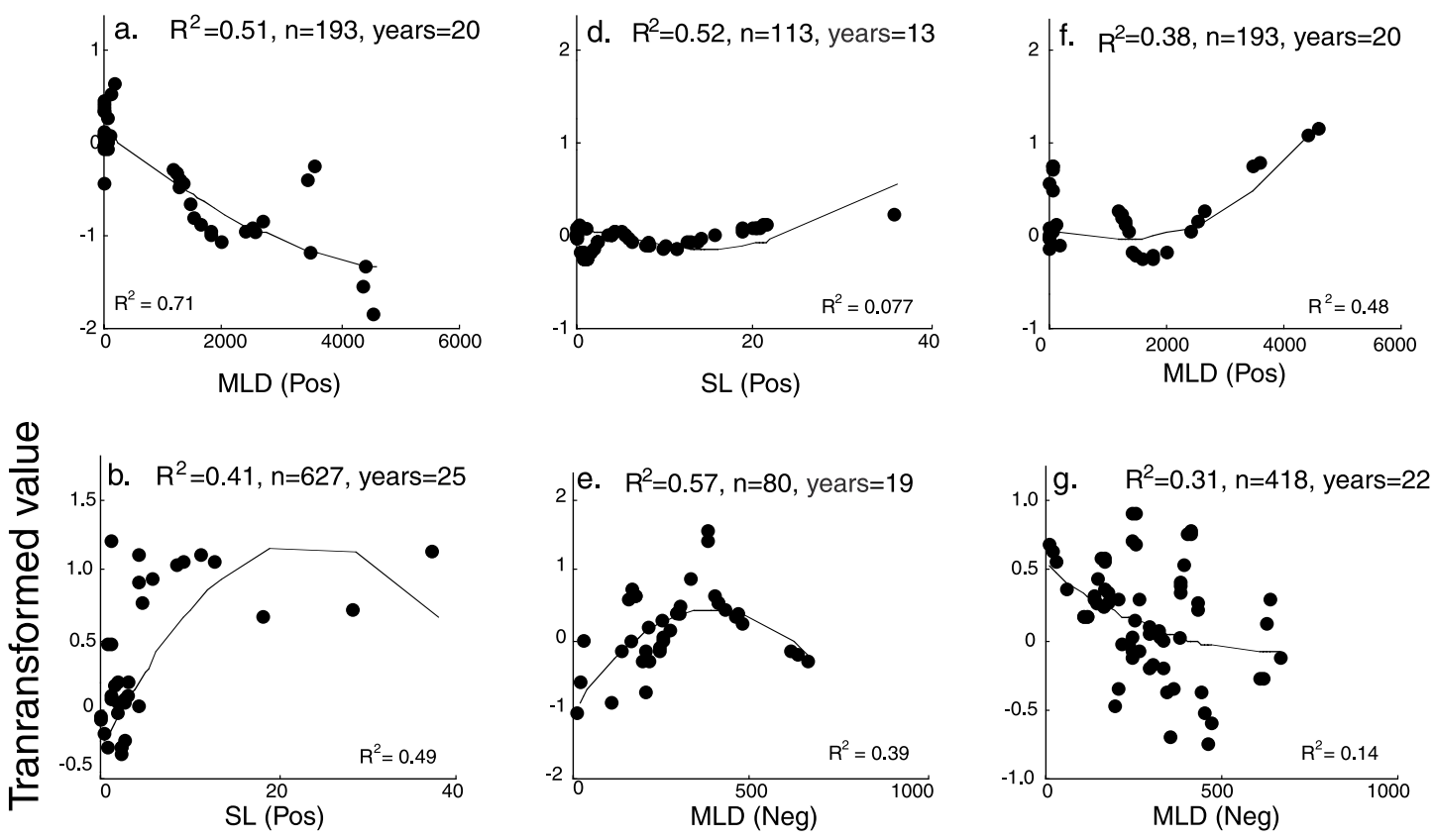

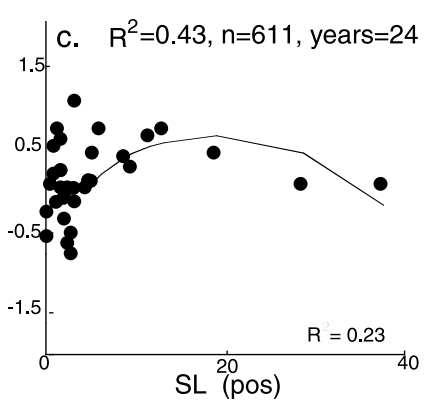

salmon. Nonlinear models were used in an exploratory manner to identify the most important single environmental variable associated with variance in salmon survival and size. The increase in variance explained by nonlinear additive models over linear multiple regression using the ACE algorithm depends on the degree of nonlinearity in the relationship. Inspection and analysis of the transformation plots during analyses showed that most of the relationships were better described by log or polynomial functions than by linear relationships.

The amount of variance explained by models using environmental conditions during different time periods of a salmon's ocean life showed that the influence of environmental conditions on size and survival was not always greatest when the fish were first released. Consideration of all the models suggested that survival was, on average, explained best by models that incorporated environmental variability at times after release. Similarly, considering the average of all

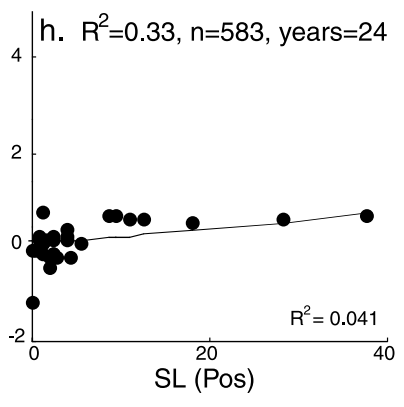

models, jack and adult size were influenced most by conditions after release.

Overall, calculating the environmental variables as the total amount of the condition above or below a threshold in the time period led to models explaining more variance than models using mean or proportional measures of the variables. Conceptually, this is similar to the degree-day idea in developmental biology; a similar approach has been used to explain effects of environmental variability on appendicularian abundance (Taggart and Frank 1987) and coho survival (Cole 2000). Most studies just use mean conditions to describe the environment; these results suggest that other approaches like cumulative conditions should be considered. Analyses based on the average of all models may be problematic as this approach requires that all environmental variables or all time periods be averaged together. Different environmental variables may act most strongly at different 
Fig. 5. Cluster 3 (south) environmental variable transformations from the best nonlinear model (highest $R^{2}$ ). The $R^{2}$ for the model, number of observations, and number of years that the observations covered are shown at the top of each panel. The environmental variable and calculation method for each best model is indicated on the $x$ axes. The shape of each transformation relationship indicates the relationship of the environmental variable to each response variable, and these have been approximated with second-order polynomials. The $R^{2}$ for these fitted polynomial relationships is also shown for each panel. The response variable and time period for the environmental variables for each panel are $(a)$ survival, release period; $(b)$ survival, jack return period; $(c)$ survival, adult return period; $(d)$ jack size, release period; $(e)$ jack size, jack return period; $(f)$ adult size, release period; $(g)$ adult size, jack return period; $(h)$ adult size, adult return period. The relationship between jack size at return and environmental conditions when adults return was not examined, as it had no biological basis.
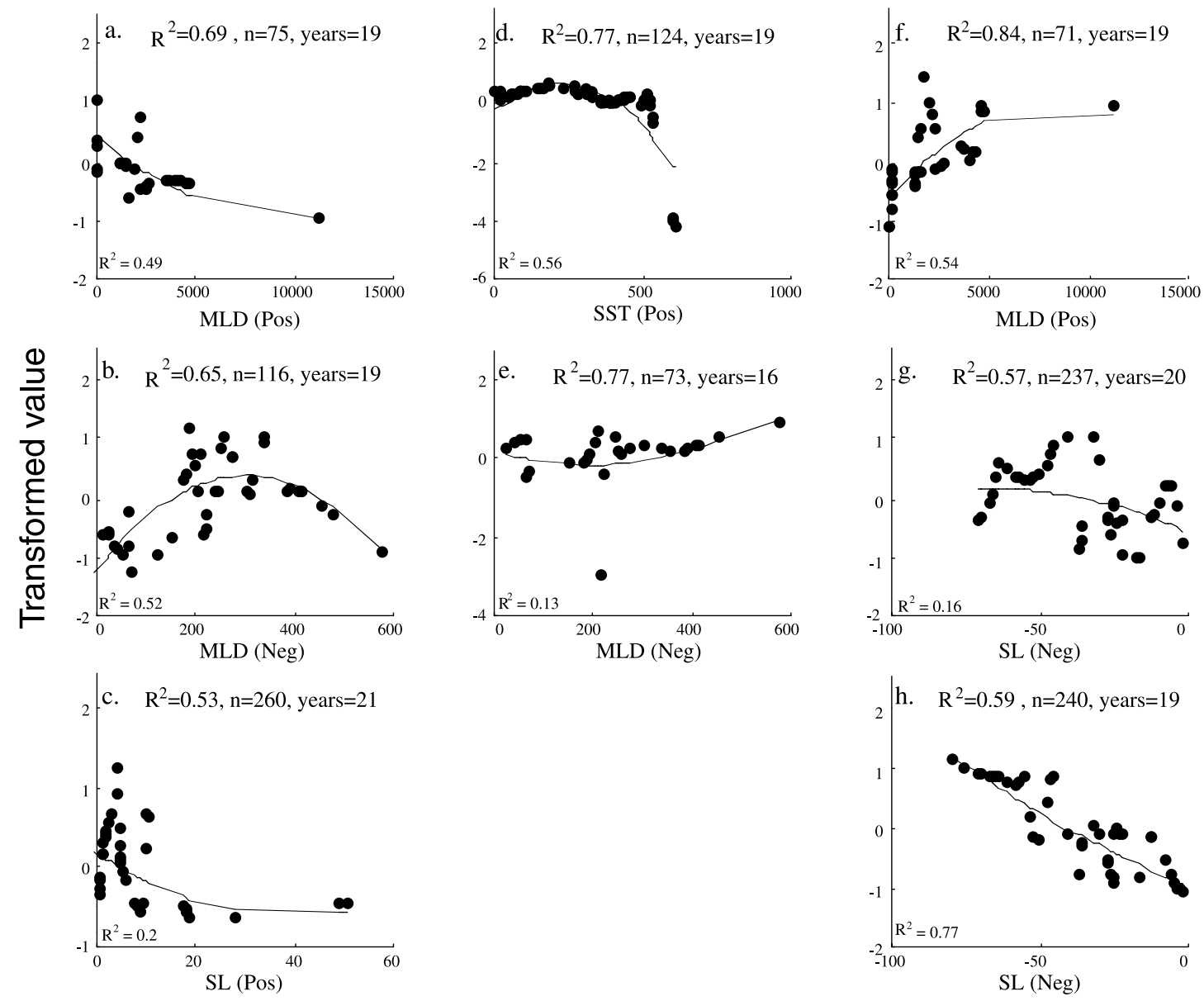

times of a salmon's ocean life. To understand which environmental variable acts most strongly at each time, the models were considered separately for each time period.

The best models (highest $R^{2}$ ) incorporated the sum of positive or negative events, indicating that the total amount of the conditions experienced was most important, not the mean conditions during the period of time considered. Analysis of the best models showed that survival was most influenced by variance in conditions at the time of release in cluster 2 (Puget Sound - Strait of Georgia) and cluster 3 (south) and at the time of return in cluster 1 (north). This contrasted with the pattern uncovered by considering the average of all models, which suggested that later time periods were more important in all regions. The most important time period for environmental influence of jack size from consideration of the best models was also different. Environmental conditions in the two time periods that might influence jack size, during release and during jack return, explained similar amounts of variance. Again, in contrast to the pattern using all models, the best models revealed that most variance in adult size was explained by models that incorporated environmental data during the time of release in all three regions. The greatest success in explaining variance via environmental variables was in the south and north; Puget Sound - Strait of Georgia models did most poorly. This suggests that either environmental variation is less important in this area or more important environmental variables were missed (discussed further below). Otherwise, these central populations have a reasonably close relationship with biological features in the south.

The most important environmental variable, as indicated by the highest average amount of variance explained by the best models, was MLD, used 12 out of 24 possible times. The mixed layer is the result of the cumulative effects of turbulence in the mixing layer (Brainerd and Gregg 1995) and factors affecting stratification such as freshwater inputs and seasonal warming. The upper mixed layer is separated from deeper waters by a change in density that impedes dif- 
fusive mixing of nutrients across the boundary. Interannual changes in MLD have been cited as the mechanism through which variation in the atmosphere produces variation in the biological properties of the ecosystem (Venrick et al. 1987; Polovina et al. 1995). A shallow mixed layer (as indicated by a small sum of daily MLD > $30 \mathrm{~m}$ ) was associated with increased survival in all three regions. A shallow mixed layer is typically associated with increased plankton production (Polovina et al. 1995), which is likely to promote survival (as observed here), whereas a deeper mixed layer may be associated with reduced production of the zooplankton, which may in turn reduce salmonid survival (Parsons and Kessler 1987). A deeper mixed layer may also increase the relative dispersion of prey (Lasker 1981).

In contrast to survival, a deeper MLD was associated with larger adult size in the most important time period in clusters 2 and 3 (and in cluster 1, but not in the most important time period), and larger jack size in cluster 3. This indicates that conditions promoting increased survival (e.g., shallow MLD) may not lead to increased size. Differing trends of survival and size tempt one to consider density-dependent mechanisms. Limited evidence does suggest that density-dependent mechanisms operate on coho (Emlen et al. 1990; Ogura et al. 1990, but see Nickelson 1986) and chinook (Beamish et al. 1995) salmon during the marine phase. The finding that MLD was important in all three regions yet that the three regions had temporally differing patterns of size and survival suggests that MLD may vary temporally between these regions. In fact, average MLD is uncorrelated between the three regions (L. deWitt, Pacific Fisheries Environmental Laboratory, 1352 Lighthouse Ave., Pacific Grove, CA 93950, personal communication).

Sea level was the second most important environmental variable, as shown by the analysis of all of the models and of just the best models, when it was used eight times. In general, inspection of the transformation relationships from the best models showed that lower sea level was associated with both increased fish size and survival in the south but was less important in the north. Lower sea level is associated with increased transport from the north and typically higher nutrient waters in the California current (McGowan et al. 1998). The sources waters from the Subarctic (North Pacific) current, however, may have varying nutrient content dependent on the proportion of water from subtropical origin, which depends on midlatitude wind stress (Parrish et al. 2000).

SST was the most important environmental variable in only three of the 24 best models, in which it was related to jack size in the southern cluster and to survival and adult size at the time of release in the northern cluster. Previous studies of environmental variation have implicated SST as an important influence on coho survival (e.g., Ryding and Skalski 1999; Cole 2000); however, the set of environmental variables considered here is greater. Although our results do not suggest that SST is unimportant, its effects appear less influential than MLD and sea level. SST is related to these variables, however, so it is possible that previous studies have found a correlative variable, rather than the underlying variable. Indeed MLD and sea level may in turn be correlated with a more primary and as yet unknown causative environmental variable.
Wind, measured as either the $v$ component (the principal forcing for upwelling) or (wind speed) ${ }^{3}$ (an index of mixing), was also less important for coho size and survival. Coho smolts may be too large when they enter the ocean to be affected by turbulence-induced disruption of prey aggregation as suggested for some marine fish larvae (Peterman and Bradford 1987). Upwelling was the least important variable in explaining variance in coho salmon size and survival. Upwelling was found to be an important predictor of coho survival before about 1981 (Nickelson 1986), but not afterwards (Pearcy 1992). Much of the data in this study is from releases after 1982 and so any effect of the previously reported upwelling relationship may be obscured.

Other environmental influences on salmon production not addressed in this study include freshwater inputs and plumes. Salmon abundance has been found to vary with river discharge in some regions (Pearcy 1992). River inputs may influence the distribution of smolts (e.g., advection), the physical environment (e.g., stratification), food availability, and predation risk (Pearcy 1992; Gargett 1997), all of which may affect size and survival. Freshwater input is likely to be important for the Strait of Georgia - Puget Sound area (Beamish et al. 1995), which did have the lowest variance explained by the set of environmental variables used in this study. The Columbia River exits in the area covered by cluster 3 and so runoff might also be important in this region (Pearcy 1992).

A biological response that we have not considered is the manner in which environmental factors influence migration. In a tagging study over a period of 7 years, Kallio-Nyberg et al. (1999) noted that environmental factors had a strong influence on migratory route in young Atlantic salmon and that prey abundance influenced migratory distances. Although our cluster results suggest that animals within clusters are influenced by coherent patterns of environmental variability, coho salmon may respond similarly and demonstrate interannual variability in spatial and temporal patterns of ocean utilization. Further research will be needed to address this question in coho salmon.

\section{Scales of environmental variation}

Biotic responses to environmental variation exist at several spatial and temporal scales, and analyses of potential relationships must take this into account. Changes at a large scale, the coupled ocean-atmosphere system, can lead to changes in those environmental variables used here, affecting primary production and food webs that support higher trophic production (Bakun 1999). Ultimately, environmental variation affects survival and growth at the individual level, and so consideration of small scales may best expose the causative environmental relationships.

In this study, we show that at the fine scale of individual salmon releases, environmental variables can account for variance in size and survival, two components of salmon production. Three larger spatial regions along the coast of North America where the size and survival of coho salmon has similar patterns were identified, suggesting that environmental variation acts similarly over these large regions.

The relationship observed between environmental and biological variables may change with increasing spatial and temporal scales and also over different time periods. For 
example, the regional relationship between upwelling and coho survival changed in the early 1980s (Nickelson 1986; Pearcy 1992). Koslow et al. (2001) showed that annual survival on a regional scale (measured as OPI) was related to a suite of variables and some of the relationships were opposite to those observed here. Their analysis extended over a longer period of time, and so changes in the relationships might be expected given the current understanding of regime shifts (Steele 1996; Hare et al. 1999; Beamish et al. 2000).

In fact, caution is required in examination of environmental relationships over a long period of time covering several regimes, because individual relationships that exist in one regime may be blurred or dominated by those existing in another period (Parrish et al. 2000). Analysis at the larger spatial and temporal scales, while providing for robust relationships, also risks obscuring the mechanisms responsible for variation, whereas at the smaller scales, too much variation can also obscure relationships. We accept that at different time periods than considered here, other variables may become more important or the same variables may act in different ways. Unfortunately, the exploratory nature of this study restricts the generalizations and inferences that may be made compared with a more statistical or hypothesis-driven study.

We have identified particular time periods and environmental variables that influence size and survival at a fine scale of individual salmon releases over a wide latitudinal range. Further understanding of the effect of variability in the coastal environment on survival and size at different life stages, however, requires improved knowledge of where, when, and how juvenile and adult salmon use particular habitats. This can come from experimental net captures, experimental fishing, traditional recovery-based tagging (including CWT), acoustic tagging, and trophic studies (Brodeur et al. 2000). In particular, our results and those of Koslow et al. (2001) suggest the importance of fieldwork to describe the biotic and abiotic conditions associated with mixed layers of varying depths in the regions identified here. This can be followed by experiments to examine how conditions in a shallow (deep) mixed-layer depth result in increased (decreased) survival and decreased (increased) size in coho salmon through exploration of physiological, feeding, competition, and predation relationships.

\section{Acknowledgments}

The ideas and analyses in this manuscript were clarified and focused by discussions with Jan Mason, Roy Mendelssohn, Frank Schwing, Mark Pickett, Tony Koslow, James Cole, Conrad Mahnken, and Richard Parrish. Assistance with obtaining and processing data was provided by Lynn DeWitt, Roy Mendelssohn, Laurie Weitcamp, Lee Blankenship, Jim Longwill, and Ken Johnson. Suggestions by Roy Mendelssohn, James Cole, James Schumacher, Joe Fisher, Bill Pearcy, Tony Koslow, the Editor, and three anonymous reviewers have improved the quality and clarity of the manuscript. This work was conducted while the first author held a postdoctoral research associateship from the National Research Council, funded by the Pacific Fisheries Environmental Laboratory, NOAA/NMFS.

\section{References}

Bakun, A. 1973. Coastal upwelling indices: west coast of North America 1946-71. U.S. Department of Commerce, NOAA Tech. Rep. NMFS SSRF-671.

Bakun, A. 1999. A dynamic scenario for simultaneous regimescale marine population shifts in widely separated large marine ecosystems of the Pacific. In Large marine ecosystems of the Pacific Rim: assessment, sustainability, and management. Edited by K. Sherman and Q. Tang. Blackwell Science, Inc., Cambridge, Mass. pp. 2-26.

Beamish, R.J., Riddell, B.E., Neville, C.E.M., Thomson, B.L., and Zhang, Z.Y. 1995. Declines in chinook salmon catches in the Strait of Georgia in relation to shifts in the marine environment. Fish. Oceanogr. 4: 243-256.

Beamish, R.J., Mahnken, C., and Neville, C.M. 1997. Hatchery and wild production of Pacific salmon in relation to large-scale, natural shifts in the productivity of the marine environment. ICES J. Mar. Res. 54: 1200-1215.

Beamish, R.J., McFarlane, G.A., and Thomson, R.E. 1999. Recent declines in the recreational catch of coho salmon (Oncorhynchus kisutch) in the Strait of Georgia are related to climate. Can. J. Fish. Aquat. Sci. 56: 506-515.

Beamish, R.J., Noakes, D.J., McFarlane, G.A., Pinnix, W., Sweeting, R., and King, J. 2000. Trends in coho marine survival in relation to the regime concept. Fish. Oceanogr. 9: 114-119.

Bradford, M.J., Myers, R.A., and Irvine, J.R. 2000. Reference points for coho salmon (Oncorhynchus kisutch) harvest rates and escapement goals based on freshwater production. Can. J. Fish. Aquat. Sci. 57: 677-686.

Brainerd, K.E., and Gregg, M.C. 1995. Surface mixed and mixing layer depths. Deep-Sea Res. Part I, Oceanogr. Res. Pap. 42: 1521-1543.

Breiman, L., and Freidman, J.H. 1985. Estimating optimal transformations for multiple regression and correlation. J. Am. Stat. Assoc. 80: 580-619.

Brodeur, R.D., Boehlert, G.W., Casillas, E., Eldridge, M.B., Helle, J.H., Peterson, W.T., Heard, W.R., Lindley, S., and Schiewe, M.H. 2000. A coordinated research plan for estuarine and ocean research on Pacific salmon. Fisheries (Bethesda), 25: 7-16.

Chelton, D.B. 1984. Commentary: short-term climatic variability in the northeast Pacific Ocean. In The influence of ocean conditions on the production of salmonids in the North Pacific. Edited by W.G. Pearcy. Oregon Sea Grant Program Publ. ORESU-W83-001, Oregon State University, Corvallis. pp. 87-99.

Cole, J. 2000. Coastal sea surface temperature and coho salmon production off the north-west United States. Fish. Oceanogr. 9: $1-16$.

Coronado, C., and Hilborn, R. 1998. Spatial and temporal factors affecting survival in coho salmon (Oncorhynchus kisutch) in the Pacific Northwest. Can. J. Fish. Aquat. Sci. 55: 2067-2077.

Cury, P., and Roy, C. 1989. Optimal environmental window and pelagic fish recruitment success in upwelling areas. Can. J. Fish. Aquat. Sci. 46: 670-680.

Cury, P., Roy, C., Mendelssohn, R., Bakun, A., Husby, D., and Parrish, R.H. 1995. Moderate is better: exploring nonlinear climatic effects on the Californian northern anchovy (Engraulis mordax). Can. Spec. Publ. Fish. Aquat. Sci. 121: 417-424.

Emlen, J.M., Reisenbichler, R.R., McGie, A.M., and Nickelson, T.E. 1990. Density-dependence at sea for coho salmon (Oncorhynchus kisutch). Can. J. Fish. Aquat. Sci. 47: 1765-1772.

Fleming, I.A., and Gross, M.R. 1990. Latitudinal clines: a trade-off between egg number and size in Pacific salmon. Ecology (Washington, D.C.), 71: 1-11. 
Francis, R.C., and Hare, S. 1994. Decadal-scale regime shifts in the large marine ecosystems of the Northeast Pacific: a case for historical science. Fish. Oceanogr. 3: 279-291.

Friedland, K.D., Hansen, L.P., Dunkley, D.A., and MacLean, J.C. 2000. Linkage between ocean climate, post-smolt growth, and survival of Atlantic salmon (Salmo salar L.) in the North Sea area. ICES J. Mar. Sci. 57: 419-420.

Gargett, A.E. 1997. The optimal stability 'window': a mechanism underlying decadal fluctuations in North Pacific salmon stocks? Fish. Oceanogr. 6: 109-117.

Hare, S., Mantua, N.J., and Francis, R.C. 1999. Inverse production regimes: Alaska and west coast Pacific salmon. Fisheries (Bethesda), 24: 6-14.

Houde, E.D. 1997. Patterns and trends in larval-stage growth and mortality of teleost fish. J. Fish Biol. 51(Suppl. A): 52-83.

Johnson, J.K. 1990. Regional overview of coded wire tagging of anadromous salmon and steelhead in Northwest America. Am. Fish. Soc. Symp. 7: 782-816.

Kallio-Nyberg, I., Peltonen, H., and Rita, H. 1999. Effects of stockspecific and environmental factors on the feeding migration of Atlantic salmon (Salmo salar) in the Baltic Sea. Can. J. Fish. Aquat. Sci. 56: 853-861.

Koslow, J.A., Hobday, A.J., and Boehlert, G.W. 2001. Climate variability and marine survival of coho salmon (Oncorhynchus kisutch) off the coast of California, Oregon and Washington. Fish. Oceanogr. In press.

Lasker, R. 1981. The role of a stable ocean in larval fish survival and subsequent recruitment. In Marine fish larvae. Edited by R. Lasker. University of Washington Press, Seattle. pp. 80-88.

Levitus, S., Boyer, T.P., Conkright, M.E., O'Brien, T., Antonov, J., Stephens, C., Stathoplos, L., Johnson, D., and Gelfeld, R. 1998. NOAA atlas NESDIS 18, World Ocean Database 1998. Vol. 1. Introduction. U.S. Government Printing Office, Washington, D.C.

Mahnken, C., Ruggerone, G., Waknitz, W., and Flagg, T. 1998. A historical perspective on salmonid production from Pacific Rim hatcheries. North Pacific Anadromous Fish Commission Bull. 1: $38-53$.

Mantua, N.J., Hare, S., Zhang, Y., Wallace, J.M., and Francis, R.C. 1997. A Pacific interdecadal climate oscillation with impacts on salmon production. Bull. Am. Meteorol. Soc. 78: 1069-1079.

McGowan, J.A., Cayan, D., and Dorman, L.M. 1998. Climateocean variability and ecosystem response in the northeast $\mathrm{Pa}-$ cific. Science (Washington, D.C.), 281: 210-216.

Mendelssohn, R., and Roy, C. 1996. Comprehensive ocean dataset extraction user's guide. U.S. Department of Commerce, NOAA Tech. Mem. NMFS-SWFSC-228.

Myers, K.W., Aydin, K.Y., Walker, R.V., Fowler, S., and Dahlberg, M.L. 1996. Known ocean ranges of stocks of Pacific salmon and steelhead as shown by tagging experiments 1956-1995. North Pacific Anadromous Fish Commission Doc. 192, Vancouver, B.C.

Nickelson, T.E. 1986. Influences of upwelling, ocean temperature, and smolt abundance on marine survival of coho salmon (Oncorhynchus kisutch) in the Oregon [USA] production area. Can. J. Fish. Aquat. Sci. 43: 527-535.

Ogura, M., Ishida, Y., and Ito, S.O. 1990. Growth variation of coho salmon (Oncorhynchus kisutch) in the western North Pacific. Nippon Suisan Gakkaishi, 57: 1089-1093.

Parrish, R.H., Schwing, F.B., and Mendelssohn, R. 2000. Midlatitude wind stress: the energy source for climatic shifts in the North Pacific Ocean. Fish. Oceanogr. 9: 224-238.

Parsons, T.R., and Kessler, T.A. 1987. An ecosystem model for the assessment of plankton production in relation to the survival of young fish. J. Plankton Res. 9: 125-137.
Pearcy, W.G. 1992. Ocean ecology of North Pacific salmonids. University of Washington Press, Seattle.

Peterman, R.M., and Bradford, M.J. 1987. Wind speed and mortality rate of a marine fish, the northern anchovy (Engraulis mordax). Science (Washington, D.C.), 235: 354-357.

Peterman, R.M., Pyper, B.J., Lapointe, M.F., Adkison, M.D., and Walters, C.J. 1998. Patterns of covariation in survival rates of British Columbian and Alaskan sockeye salmon (Oncorhynchus nerka) stocks. Can. J. Fish. Aquat. Sci. 55: 2503-2517.

Polovina, J.J., Mitchum, G.T., and Evans, G.T. 1995. Decadal and basin-scale variation in mixed layer depth and the impact on biological production in the Central and North Pacific 1960-88. Deep-Sea Res. Part I, Oceanogr. Res. Pap. 42: 1701-1716.

Pyper, B.J., Peterman, R.M., Lapointe, M.F., and Walters, C.J. 1999. Patterns of covariation in length and age at maturity of British Columbia and Alaska sockeye salmon (Oncorhynchus nerka) stocks. Can. J. Fish. Aquat. Sci. 56: 1046-1057.

Reid, J.L., and Mantyla, A.W. 1976. The effect of geostrophic flow upon coastal sea level elevations in the northern North Pacific Ocean. J. Geophys. Res. 81: 3100-3110.

Ricker, W.E. 1995. Trends in the average size of Pacific salmon in Canadian catches. Can. Spec. Publ. Fish. Aquat. Sci. 121: 593-602.

Ryding, K.E., and Skalski, J.R. 1999. Multivariate regression relationships between ocean conditions and early marine survival of coho salmon (Oncorhynchus kisutch). Can. J. Fish. Aquat. Sci. 56: $2374-2384$.

Sandercock, F.K. 1991. Life history of coho salmon. In Pacific salmon life histories. Edited by C. Groot and L. Marcolis. UBC Press, Vancouver, B.C. pp. 395-445.

Sinclair, M., and Iles, T.D. 1988. Population richness of marine fish species. Aquat. Living Resour. 1: 71-83.

Solazzi, M.F., Nickelson, T.E., and Johnson, S.L. 1991. Survival, contribution, and return of hatchery coho salmon (Oncorhynchus kisutch) released into freshwater, estuarine, and marine environments. Can. J. Fish. Aquat. Sci. 48: 248-253.

Steele, J.H. 1996. Regime shifts in fisheries management. Fish. Res. 25: 19-23.

Strub, P.T., Allen, J.S., Huyer, A., Smith, R.L., and Beardsley, R.C. 1987. Seasonal cycles of currents, temperatures, winds and sea level over the northeast Pacific continental shelf: $35^{\circ} \mathrm{N}$ to $48^{\circ} \mathrm{N}$. J. Geophys. Res. 92: 1507-1526.

Taggart, C.T., and Frank, K.T. 1987. Coastal upwelling and Oikopleura occurrence ("slub"): a model and potential application to inshore fisheries. Can. J. Fish. Aquat. Sci. 44: 1729-1736.

Tyler, A.V. 1992. A context for recruitment correlations: why marine fisheries biologist should still look for them. Fish. Oceanogr. 1: 97-107.

Venrick, E.L., McGowan, J.A., Cayan, D., and Hayward, T.L. 1987. Climate and chlorophyll a: long-term trends in the central North Pacific Ocean. Science (Washington, D.C.), 238: 70-72.

Ware, D.M., and McFarlane, G.A. 1989. Fisheries production domains in the northeast Pacific Ocean. In Effects of ocean variability on recruitment and an evaluation of parameters used in stock assessment models. Edited by R.J. Beamish and G.A. McFarlane. Can. Spec. Publ. Fish. Aquat. Sci. 108. pp. 359-379.

Weitkamp, L.A., Wainwright, T.C., Bryant, G.J., Milner, G.B., Teel, D.J., Kope, R.G., and Waples, R.S. 1995. Status review of coho salmon from Washington, Oregon, and California. U.S. Department of Commerce, NOAA Tech. Mem. NMFS-NWFSC-24.

Welch, D.W., Ward, B.R., Smith, B.D., and Eveson, J.P. 2000. Influence of the 1989/90 ocean climate shift on British Columbia steelhead (Oncorhynchus mykiss) populations. Fish. Oceanogr. 9: 17-32. 